\title{
Stres Akulturatif Pada Mahasiswa Luar Jawa Yang Studi Di Universitas 17 Agustus 1945
}

\author{
Hengki Hendra Pradana ${ }^{1}$ \\ Program Studi Magister Psikologi Universitas 17 Agustus 1945 Surabaya \\ hengkihendra007@gmail.com \\ Suryanto ${ }^{2}$ \\ Psikologi Universitas 17 Agustus 1945 Surabaya \\ suryanto@psikologi.unair.ac.id \\ Tatik Meiyuntariningsih ${ }^{3}$ \\ Psikologi Universitas 17 Agustus 1945 Surabaya \\ tatikmeiyun@untag-sby.ac.id
}

\begin{abstract}
This study aims to (1) describe the forms of acculturation stress, (2) determine the coping stress acculturation of students studying at the University of 17 August 1945 Surabaya. This study using a qualitative approach and using the phenomenological method. This time doing research in the area of the University of 17 August 1945 Surabaya, because Untag is a multicultural university. Data collection techniques using in-depth interviews (in-depth interviews) and observation. The subjects in this study were 3 new students aged 18-20 years who came from outside Java. The results of this study are forms of acculturation stress experienced by the subject are a) Difficulty adapting to a new environment, b) Learning difficulties, c) Discomfort due to differences in food, d) Feeling isolated, e) Difficulty in the direction of the road. While the acculturation form of stress coping is as follows: a) Asking for help, b) Studying more diligently c) Taking the initiative to cook by himself d) Trying to get closer to college friends, e) Trying to ask friends. Based on the results of this study, it is hoped that new students from outside Java are advised to increase their ability to adapt to new environments. For further research, it is hoped that the results of this study can be used as a reference for conducting further research to make it better and perfect.
\end{abstract}

Keywords: Stress Acculturation, Newcomer Student

\begin{abstract}
Abstrak
Penelitian ini bertujuan untuk (1) mendeskripsikan bentuk-bentuk stres akulturasi, (2) mengetahui coping stres akulturasi mahasiswa yang studi di Universitas 17 Agustus 1945 Surabaya. Dalam penelitian ini menggunakan pendekatan kualitatif dan menggunakan metode fenomenologi. Kali ini melakukan penelitian di kawasan Universitas 17 Agustus 1945 Surabaya, dikarenakan Untag adalah perguruan tinggi multikultural. Teknik pengumpulan data menggunakan wawancara mendalam (in-
\end{abstract}


depth interview) dan observasi. Subjek dalam penelitian ini adalah Mahasiswa baru usia 18-20 tahun yang berjumlah 3 orang dan berasal dari luar Jawa. Hasil penelitian ini merupakan bentuk-bentuk stres akulturasi yang dialami oleh subjek adalah a) Kesulitan beradaptasi dengan lingkungan yang baru, b) Kesulitan belajar, c) Tidak nyaman akibat perbedaan makanan, d) Merasa terasingkan, e) Kesulitan arah jalan. Sedangkan bentuk coping stres akulturasi sebagai berikut: a) Meminta tolong, b) Belajar lebih tekun c) Berinisiatif memasak sendiri d) Berusaha lebih akrab dengan teman kuliah, e) Mencoba bertanya kepada teman. Berdasarkan hasil penelitian ini maka diharapkan kepada mahasiswa baru dari luar Jawa disarankan agar meningkatkan kemampuan beradaptasi terhadap lingkungan baru. Untuk penelitian selanjutnya, diharapkan hasil dari penelitian ini dapat dijadikan sebagai bahan acuan untuk melakukan penelitian selanjutnya agar menjadi lebih baik dan sempurna.

Kata kunci: Stres Akulturasi, Mahasiswa Pendatang

\section{PENDAHULUAN}

Universitas 17 Agustus 1945 Surabaya adalah perguruan tinggi swasta yang berada di wilayah Surabaya. Mahasiswa yang mencari ilmu di Universitas 17 Agustus 1945 tidak hanya berasal dari kota Surabaya, melainkan juga dari luar kota dan juga sampai luar Pulau Jawa. Sehingga berbagai ras, suku dan agama melebur menjadi satu di kampus yang kerap disebut Untag Surabaya. Berdasarkan hasil wawancara terhadap mahasiswa yang berasal dari luar Pulau Jawa, menunjukan ada permasalahan yang sering muncul pada saat mereka berpindah atau berdomisili di Surabaya, diantaranya adalah mereka kesulitan dalam memahami bahasa Jawa, karena mayoritas memang orang Surabaya pastinya menggunakan bahasa Jawa, sehingga hal ini menjadikan sebuah polemik tersendiri bagi mahasiswa pendatang yang berasal dari luar Pulau Jawa, mereka tidak memahami apa yang dikatakan atau apa yang dibicarakan teman-temannya dan orang yang disekitarnya. Masalah dalam hal mencari teman baru dan perihal yang berkaitan dengan pergaulan, mereka mengalami kesulitan atau kesalahpahaman dalam berkomunikasi.

Rasa canggung atau bahkan tidak nyaman karena ketidakpahaman bahasa dalam menggunakan bahasa Jawa, membuat mereka mengalami stres. Proses akulturasi merupakan suatu hal yang sulit dan sering kali menimbulkan stres (Ward et al., 2001) karena dapat muncul banyak konflik dalam diri individu ketika mereka berupaya untuk menyesuaikan atau mengurangi perbedaan-perbedaan budaya yang ditemuinya, konflik ini disebut juga dengan stres akulturatif (Born dalam mena, padilla \& Maldonado, 1987). Dari data yang dilakukan oleh peneliti pada saat mewawancarai beberapa mahasiswa mengungkapkan bahwa muncul 
permasalahan-permasalahan ketika berpindah di Kota Surabaya adalah a) Kesulitan beradaptasi dengan lingkungan yang baru, b) Kesulitan belajar, c) Tidak nyaman akibat perbedaan makanan, d) Merasa terasingkan, e) Kesulitan arah jalan.

Menurut Coleman Caplin (2011) mengungkapkan bahwa akulturasi itu terdiri dari berbagai perubahan dalam kebudayaan, yang mana perubahan itu terjadi akibat dari bertemunya dua kebudayaan sehingga menyebabkan persamaan antara dua budaya meningkat. Sedangkan menurut Koentjaraningrat (1996) akulturasi yaitu terjadinya proses sosial yang mana kelompok manusia dengan kebudayaan tertentu dihadapkan dengan kebudayaan asing yang berbeda, akhirnya munculah unsur kebudayaan asing, dan lambat laun akan diterima dan diolah atau diadaptasikan dalam kebudayaan sendiri tanpa menghilangkan identitas sendiri.

Istilah stres dalam psikologi menunjukkan yaitu suatu tuntutan atau tekanan yang dialami oleh individu atau organisme agar individu tersebut dapat beradaptasi atau menyesuaikan diri dengan lingkungannya (Nevid et al., 2002). Teori dari Berry et al. (2002) mengatakan stres akulturatif yaitu respon dari individu terhadap suatu peristiwa dalam sebuah kehidupan (yang muncul dari pertemuan antar budaya), yang mana peristiwa tersebut memiliki kemampuan yang lebih daripada individu untuk mengatasinya. Proses akulturasi yang sangat panjang dapat menimbulkan munculnya beberapa perubahan perilaku (behavioral shifts) terhadap individu yang bersangkutan. Proses tersebut juga dapat memicu konflik budaya yang lebih problematic, sehingga memunculkan stres akulturatif pada individu tersebut yang memiliki kaitan selama kontak antar budaya itu berlangsung (Berry, 2005).

Selanjutnya menurut Berry (1999) stres akulturatif yaitu tekanan atau stres yang berhubungan dengan hukum institusional, bahasa, gaya interaksi sosial, pakaian serta aturan sosial. Masih dengan menurut Berry (2004) stres juga dapat dialami oleh seseorang yang mengalami akulturasi akan tetapi bukan suatu hal yang tidak bisa dihindari. Saat melakukan kontak antar budaya, seseorang juga bisa dikatakan mengalami suatu proses akulturasi, yang mana pengalaman individu menghadapi berbagai macam perubahan yang terjadi di kehidupannya, mulai dari perubahan-perubahan yang kecil hingga ke perubahan-perubahan yang besar. Kemudian, munculah hasil dari berbagai suatu pengalaman akulturasi yang telah dihadapi individu.

Bagi beberapa individu, perubahan-perubahan akulturatif yang telah terjadi dipandang sebagai suatu stressor atau penyebab dari stres. Sebaliknya beberapa orang-orang lainnya perubahan akulturatif malah dipandang sebagai hal yang tidak membahayakan untuk diri 
sendiri. Bahkan dijadikan sebagai sebuah kesempatan atau opportunities. Dari situlah muncul dan berkembang stres akulturatif sebagai hasil dari pengalaman-pengalaman akulturasi yang telah terjadi, di mana tingkatnya beragam pada tiap-tiap individu (Berry, 2004).

Menurut Berry et al. (2006) stressor atau penyebab dari stres akulturatif biasanya muncul dalam pengalaman hidup lintas-budaya meliputi stressor fisik (iklim, daerah), biologis (makanan, penyakit), sosial (homesickness, isolasi), cultural (perbedaan nilai budaya, diskriminasi rasial), dan fungsional (bahasa, pekerjaan/sekolah, keuangan, transportasi).

Pendapat Berry et al. (2002) menjelaskan terdapat 3 bagian utama dari stres akulturasi: pertama, sebuah konteks dari masyarakat asal dan konteks dari masyarakat tujuan, bagaimana keadaan atau situasi politik, sosial, ekonomi dan juga demografis dari negara asal individu serta bagaimana sikap dan juga pandangan masyarakat dari negara tujuan pada keberagaman budaya. Kedua, faktor yang pertama sebelum akulturasi (jenis kelamin, Pendidikan, usia, alasan untuk melakukan imigrasi push/pull factor, cultural distance) dan selama proses akulturasi (durasi, strategi coping, strategi akulturasi, dukungan sosial dan sikap masyarakat dari negara tujuan). Ketiga, hasil akhir yang berupa adaptasi dari psikologis dan social cultural.

Dengan begitu coping stress ialah suatu bentuk dari upaya yang dilakukan seseorang untuk mengatasi dan meminimalisir situasi yang penuh dengan tekanan (stress) baik secara kognitif ataupun dengan sebuah perilaku. Sedangkan pendapat dari Lazarus dan Folkman (dalam Smet 1994) mengartikan coping yaitu suatu proses di mana seseorang mencoba untuk dapat mengelola jarak yang ada antara beberapa tuntutan, baik tuntutan itu yang berasal dari individu atau yang berasal dari lingkungannya dengan sumber daya yang mereka gunakan dalam menghadapi stres.

\section{METODE}

Penelitian ini menggunakan pendekatan kualitatif dengan metode fenomenologi. Subjek yaitu informan diambil karena memiliki kaitan dengan karakteristik tertentu, dan penelitian ini dilakukan di Surabaya. Karena Surabaya adalah kota metropolitan yang banyak mahasiswa pendatang yang ingin menempuh studi di perguruan tinggi. Sehingga peneliti mengambil subjek penelitian di salah satu Universitas di Surabaya, yaitu Universitas 17 agustus 1945 atau kerap disebut Untag. Penelitian ini untuk pengumpulan data menggunakan metode wawancara secara mendalam (in-depth interview). 
Informan yang digunakan dalam penelitian ini yaitu mahasiswa Untag semester pertama yang berasal dari luar Jawa. Ada beberapa karakteristik mahasiswa yang dijadikan sebagai sampel dalam penelitian adalah usia berkisar antara 18-20 tahun, mahasiswa perempuan atau laki-laki, sedang menempuh pendidikan di Universitas 17 Agustus 1945 Surabaya, berasal dari luar Jawa, belum pernah tinggal di Jawa sebelum kuliah, sejak awal masuk kuliah tinggal di sekitar kampus atau kos (tidak tinggal di rumah saudara).

Pada penelitian ini, peneliti memakai teknik analisis domain, yakni analisis yang dilakukan untuk memperoleh gambaran atau pengertian bersifat umum dan cenderung relatif menyeluruh tentang apa yang tercakup di suatu fokus atau pokok permasalahan yang sedang diteliti. Untuk mendapatkan gambaran atau pengertian yang lebih rinci dan mendalam tentang apa yang diteliti, peneliti menggunakan coding guna mempermudah peneliti untuk dapat mengelompokkan dan mensistemasi sebuah data, sehingga dapat memunculkan gambaran topik yang diteliti.

\section{HASIL DAN PEMBAHASAN}

Peneliti melakukan sebuah orientasi lapangan tentang kemungkinan dilakukannya penelitian sesuai dengan tema yang peneliti sudah ditentukan sebelumnya untuk melakukan penelitian. Orientasi ini dilakukan pada bulan Juli 2019 dengan cara melakukan wawancara awal kepada 3 mahasiswa luar Jawa yang kuliah di Untag Surabaya guna memperoleh gambaran umum mengenai stres akulturasi yang mereka alami pada perkuliahan di Untag.

Hasil penelitian menyatakan bentuk-bentuk stres akulturasi yang pertama adalah kesulitan beradaptasi dengan lingkungan yang baru, di mana subjek susah memahami bahasa Jawa ketika berkumpul dengan teman-temannya atau pada saat berada di lingkungan sekitar yang banyak masyarakat Jawa. Kesulitan yang dialami yaitu menyesuaikan diri dengan temanteman baru dan memiliki masalah interaksi dengan teman, ketika bercanda bersama atau membicarakan hal-hal yang menggunakan bahasa Jawa maka subjek merasa bingung dan tidak paham apa yang di menjadi topik pembahasan oleh teman-temannya dan subjek hanya bisa tersenyum tanpa memahami apa yang dibicarakan. Yang kedua adalah kesulitan belajar dan kuliah, yang mana subjek harus mengejar ketertinggalan dan menurut subjek tingkat pendidikan di Jawa lebih maju daripada di luar Jawa, sehingga rasa minder muncul dari diri subjek. Ketiga tidak nyaman akibat perbedaan makanan, menurut subjek makanan di daerah asal dan di Surabaya memiliki perbedaan rasa sehingga subjek awal-awal tidak begitu nafsu 
makan. Keempat merasa kesepian, hidup jauh dari keluarga sangat terasa bagi subjek dimana tidak ada orang satupun yang dikenal, sehingga setiap pulang kuliah subjek langsung pulang ke kos dan berdiam diri di kamar kos. Kelima kesulitan arah jalan, merasa asing dirasakan subjek pada saat berada di Surabaya, buta arah dan tidak tahu lokasi mana-mana membuat subjek bingung dan takut untuk keluar meski hanya sekedar jalan-jalan, sehingga subjek hanya bermain di sekitaran daerah kampus.

Hasil penelitian lainnya menunjukkan coping stres akulturasi mahasiswa yang studi di Universitas 17 Agustus 1945 Surabaya yaitu sebagai berikut, pertama subjek meminta tolong secara sopan kepada orang lain yang menggunakan bahasa Jawa untuk mengganti ke Bahasa Indonesia agar subjek memahami apa yang dibicarakan, subjek juga belajar dan mencoba bertanya kepada teman-teman tentang bahasa Jawa, minimal bisa memahami apa yang dibicarakan oleh orang Jawa. Kedua yaitu dengan mengulang materi kuliah setiap malam, membaca-baca buku pelajaran dan menyelesaikan tugas kuliah sebelum deadline untuk mengatasi kesulitan dalam belajar saat kuliah berlangsung, biasanya minta pertolongan kepada teman dekat untuk menjelaskan tugas kuliah, bertanya tentang materi perkuliahan pada kakak senior. Ini adalah bentuk coping dari keaktifan diri yakni suatu tindakan yang mencoba untuk menghilangkan atau meminimalisir penyebab stres serta untuk memperbaiki akibatnya, dengan kata lain adalah usaha seseorang untuk coping, yaitu dengan bertindak secara langsung. Ketiga, perbedaan masakan Surabaya dengan daerah asal mengakibatkan subjek memasak sendiri makanan khas daerah mereka. Subjek merasa tidak cocok dengan masakan Surabaya karena memang belum terbiasa, sehingga berinisiatif memasak sendiri. Usaha tersebut merupakan bentuk dari coping yang termasuk keaktifan diri. Keempat mencoba berhubungan lebih akrab dengan teman kuliah, subyek berusaha untuk akrab dengan teman kosnya. Mencari kelompok atau organisasi daerah asalnya (Ormada) dan ikut Unit Kegiatan Mahasiswa (UKM) agar tidak merasa kesepian. Kelima yaitu subjek mencoba bertanya kepada teman kos, teman kelas yang paham jalan Surabaya, subjek meminta petunjuk arah dan lokasi mana yang hendak dituju subjek.

Berdasarkan hasil observasi menunjukkan subjek masih dalam proses untuk beradaptasi, akan tetapi mempunyai keyakinan untuk bisa beradaptasi karena telah memasuki semester 3 dan sudah mulai terbiasa dengan keadaan di lingkungannya yang baru. Subjek tidak lagi takut sendirian karena telah memiliki banyak teman yang dikenal. Hal ini disebut 
impersitive menurut Pareek (Rahayu, 2005) yaitu individu merasa optimis atau percaya bahwa ia mampu menyelesaikan masalah dan keadaan akan membaik kembali.

\section{SIMPULAN}

Berdasarkan dari hasil pembahasan pada penelitian yang telah dilakukan pada mahasiswa luar Jawa yang mengalami stres akulturatif di Universitas 17 Agustus 1945 Surabaya dapat diambil kesimpulan bahwa ada beberapa bentuk-bentuk stres akulturasi yang dialami oleh mahasiswa yang berada di Surabaya, yaitu kesulitan beradaptasi dengan lingkungan yang baru, kesulitan belajar dan kuliah, tidak nyaman akibat perbedaan makanan, merasa kesepian, kesulitan mencari arah jalan dan bentuk coping stres akulturasi yang dilakukan oleh mahasiswa yang berasal dari luar Jawa yaitu meminta tolong secara sopan kepada orang lain yang menggunakan bahasa Jawa untuk mengganti ke bahasa Indonesia, belajar materi kuliah setiap malam, membaca buku pelajaran dan mengerjakan tugas kuliah sebelum deadline, tidak cocok dengan masakan Surabaya, sehingga berinisiatif memasak sendiri, berhubungan lebih akrab dengan teman kuliah, atau teman kosnya, mencari kelompok atau organisasi Unit Kegiatan Mahasiswa (UKM), mencoba bertanya kepada teman kos, teman kelas yang paham jalan Surabaya, meminta petunjuk arah dan lokasi mana yang hendak dituju subjek.

Saran bagi subjek penelitian dan individu lain yang sedang merantau untuk mencari ilmu. Individu diharapkan untuk mampu dalam menghadapi stres akulturatif dengan bentukbentuk coping yang positif, sehingga merasa nyaman tinggal di daerah yang baru, khususnya di kota Surabaya. Bagi pelajar dari luar Jawa yang ingin meneruskan kuliah di Jawa. Penelitian ini diharapkan dapat dijadikan model coping bagi pelajar dari luar Jawa yang ingin meneruskan Pendidikan di Jawa, sehingga mampu beradaptasi melalui coping stres akulturatif yang positif.

Banyak kekurangan di dalam penelitian ini, sehingga perlu evaluasi. Bagi penelitian selanjutnya, diharapkan penelitian ini dapat dijadikan sebagai masukan serta acuan dan juga dapat dijadikan rujukan dalam melakukan sebuah penelitian selanjutnya, supaya menjadi lebih baik dan sempurna..

\section{DAFTAR PUSTAKA}

Berry, W. J,dkk. (1999). Psikologi Lintas-Budaya: Riset dan Aplikasi. Jakarta: PT Gramedia Pustaka Utama. 
Berry, W. J, Poortinga, Y. H, Segall, M, H., \& Dosen P. R. (2002). Cross-Cultural Psychology: Research and applications (2nd ed.). UK: Cambridge University Press.

Berry, W. J. (2005). Acculturation: Living Successfully in Two Cultures. International Journal of Intercultural Relation, 29(6), 697-712.

Chaplin, C. P. (2000). Complete Dictionary of Psychology. Jakarta: PT. Raja Grafindo Persada.

Gulo W. (2002). Research methodology. Jakarta: Grasindo.

Hidajat, V. and Sodjakusumah, T.I. (2000). Relationship Between Culture Shock and Academic Achievement. Journal of Psychology, 5(1), 46-55.

Koentjaraningrat (1996). Humans and Culture. Jakarta: Bridge.

Koentjaraningrat. (2010). Humans and Culture in Indonesia. Jakarta: Bridge.

Matsumoto, D., dan Juang L. (2008). Culture and Psychology. (4th ed). Belmont: Thomson Higher Education.

Moleong, (2011). Qualitative Research Methodology. Bandung: PT Remaja Rosdakarya.

Nevid, J.S., Rathus, S.A. and Beverly G. (2002). Abnormal Psychology. Jakarta: Erlangga.

Rahayu, K.B. (2005). Life Struggle for PLWHA (People with HIV / AIDS): A Qualitative Study of the Forms of Coping Strategies in Adolescents Infected with HIV / AIDS. Essay. (Not Published). Surakarta: Faculty of Psychology UMS.

Arikunto. (2013). Research Procedure A Practical Approach. Jakarta: Rineka Cipta.

Susetyo, D.P.B. (2010). Stereotypes and relationships between groups. First printing. Yogyakarta: Graha Science. 